\title{
Ethambutol induced optic neuritis: a case series
}

\author{
Sruthi N., Anuradha M.* \\ Department of Pharmacology, Govt. Medical College, Kozhikode, Kerala, India
}

Received: 25 October 2019

Accepted: 06 December 2019

*Correspondence:

Dr. Anuradha M.,

Email: anuradha.m1@gmail.com

Copyright: (C) the author(s), publisher and licensee Medip Academy. This is an open-access article distributed under the terms of the Creative Commons Attribution Non-Commercial License, which permits unrestricted non-commercial use, distribution, and reproduction in any medium, provided the original work is properly cited.

\begin{abstract}
Ethambutol is one of the first line chemotherapeutic agents used in the treatment of tuberculosis used both in the intensive and continuation phase according to the new Revised National Tuberculosis Control Program guidelines. Patient acceptability is rather good with this drug as it produces comparatively lesser adverse effects. The most important and serious side effect reported is optic neuritis, resulting in loss of visual acuity, color vision and field defects. The incidence of optic neuritis is generally directly proportional to the dose and duration of ethambutol therapy. Here we report four cases of ethambutol induced optic neuritis in patients on fixed dose combinations (FDC) of ethambutol, isoniazid, pyrazinamide and rifampicin who presented in Ophthalmology OPD in a span of 2 months, between June and July 2019. Contradictory to the rare occurrence of ethambutol induced optic neuritis this comparatively higher incidence of optic neuritis is alarming. We observed that the presentation of ethambutol induced optic neuritis can vary and dose of ethambutol along with other factors can also contribute to it. So proper pretreatment evaluation, dosage adjustment, periodic monitoring and early detection have a significant role in prevention and treatment of ethambutol induced optic neuritis.
\end{abstract}

Keywords: Tuberculosis, Ethambutol, Adverse effect, Optic neuritis, Fixed-dose combination

\section{INTRODUCTION}

Tuberculosis is one of the major health problem in India, it kills nearly half a million people every year. ${ }^{1}$ In India diagnosis \& treatment of tuberculosis is based on Revised National Tuberculosis Control Programme (RNTCP) guidelines. $^{2}$ Ethambutol is one of the first line anti tubercular drugs used along with isoniazid, rifampicin and pyrazinamide. ${ }^{3}$ Previously each drug was given separately as per the weight of the patient in a thrice weekly regimen. ${ }^{2}$ As per the updated RNTCP guidelines all the drug sensitive cases of tuberculosis are treated with a two month intensive phase and four month continuation phase and drugs are given in fixed dose combination (FDC) daily. The number of FDC's are decided based on the weight categories (Table 1-3). ${ }^{2,4}$
Ethambutol is an important first line drug in the treatment of tuberculosis. It has got activity against Mycobacterium tuberculosis, Mycobacterium bovis and some nonspecific Mycobacteria. It is a synthetic congener of 1, 2ethanediamine and is bacteriostatic in nature. ${ }^{3,5}$ It acts by inhibiting the enzyme arabinosyltransferase III and thus interfering with arabinogalactan synthesis, inhibiting the mycolic acid incorporation into mycobacterial cell wall. ${ }^{3}$

Ethambutol produces minimal adverse effects of which diminished visual acuity accounts for $1 \%$, rash for $0.5 \%$ and drug fever for $0.3 \%$. Other minor side effects reported were pruritus, joint pain and headache. But optic neuritis is the most important side effect that leads to decreased visual acuity, loss of red green discrimination and visual field defects. ${ }^{6}$ These effects are dose dependant and is generally reversible if detected early. ${ }^{7}$ 
The recommended average dose of ethambutol as per RNTCP guidelines is $20 \mathrm{mg} / \mathrm{kg} /$ body weight (range $15-25$ $\mathrm{mg} / \mathrm{kg} /$ day) and maximum recommended dose is 1500 $\mathrm{mg} /$ day. Optic neuritis is said to be uncommon in lower dose limits and as RNTCP guidelines is dependent on weight bands, monitoring for ethambutol induced optic neuritis is important. ${ }^{4,8}$

Table 1: RNTCP guidelines 2019.

\begin{tabular}{lll}
$\begin{array}{l}\text { Type of } \\
\text { patient }\end{array}$ & $\begin{array}{l}2 \text { months } \\
\text { intensive phase }\end{array}$ & $\begin{array}{l}4 \text { months } \\
\text { continuation phase }\end{array}$ \\
\hline $\begin{array}{l}\text { New/ } \\
\text { previously } \\
\text { treated }\end{array}$ & $2 \mathrm{HRZE}^{*}$ & $4 \mathrm{HRE}^{*}$ \\
\hline
\end{tabular}

*H: Isoniazid, R: Rifampicin, Z: Pyrazinamide, E: Ethambutol.

Table 2: Drug dosage for adult tuberculosis.

\begin{tabular}{|c|c|c|}
\hline \multirow{4}{*}{$\begin{array}{l}\text { Weight } \\
\text { category } \\
\text { (kg) }\end{array}$} & \multicolumn{2}{|l|}{ Number of FDCs } \\
\hline & Intensive phase & Continuation phase \\
\hline & HRZE* & HRE* \\
\hline & $75 / 150 / 400 / 275$ & $75 / 150 / 275$ \\
\hline 25-39 & 2 & 2 \\
\hline $40-54$ & 3 & 3 \\
\hline $55-69$ & 4 & 4 \\
\hline 70-75 & 5 & 5 \\
\hline$>75$ & 6 & 6 \\
\hline
\end{tabular}

*H: Isoniazid, R: Rifampicin, Z: Pyrazinamide, E: Ethambutol.

Table 3: Drug dosage for paediatric tuberculosis.

\begin{tabular}{|c|c|c|c|}
\hline \multirow{4}{*}{$\begin{array}{l}\text { Weight } \\
\text { category } \\
\text { (kg) }\end{array}$} & \multicolumn{3}{|c|}{ Number of FDCs (dispersible) } \\
\hline & \multicolumn{2}{|c|}{ Intensive phase } & \multirow{2}{*}{$\begin{array}{l}\text { Continuation phase } \\
\text { HRE* }\end{array}$} \\
\hline & HRZ* & $\mathbf{E}^{*}$ & \\
\hline & $50 / 75 / 150$ & 100 & $50 / 75 / 100$ \\
\hline 4-7 & 1 & 1 & 1 \\
\hline 8-11 & 2 & 2 & 2 \\
\hline 12-15 & 3 & 3 & 3 \\
\hline $16-24$ & 4 & 4 & 4 \\
\hline 25-29 & $3+1 \mathrm{~A} * *$ & 3 & $3+1 \mathrm{~A}$ \\
\hline 30-39 & $2+2 \mathrm{~A}$ & & 2 \\
\hline
\end{tabular}

*H: Isoniazid, R: Rifampicin, Z: Pyrazinamide, E: Ethambutol. **A: Adult.

\section{CASE REPORT}

\section{Case 1}

A 50 year old male weighing $94 \mathrm{kgs}$ on FDC of 5 tablets/day who had completed 6 month course of antitubercular regime, presented with defective visionof both eyes. Left eye was affected more than the right eye. On examination his visual acuity for right eye was $6 / 36$ and for left eye 2.5 meters $(\mathrm{CF})$ counting fingers, color vision was normal for right eye but defective for left eye and visual field was constricted bilaterally. Fundus examination in both eyes did not reveal any abnormalities. He was started on oral prednisone $40 \mathrm{mg}$, zinc (20 mg) and vitamin B complex and he is continuing with this treatment but there was no significant improvement noted in this patient and he is being followed up.

\section{Case 2}

A 65 year old male weighing $60 \mathrm{~kg}$ on FDC of 4 tablets /day, completed 6 months of treatment for pulmonary tuberculosis presented with bilateral defective vision. Symptoms started nearly 4 and half months after initiation of therapy, but he did not turn up for ophthalmic evaluation. On examination color vision was defective for both eyes visual acuity for right eye was $1 / 2 \mathrm{~m} \mathrm{CF}$ and for left eye it was $6 / 24$. Fundus examination was normal bilaterally. He was started on oral prednisone $40 \mathrm{mg}$, zinc $(20 \mathrm{mg})$ and vitamin B complex and he showed no significant improvement in visual parameters till the last follow up.

\section{Case 3}

A 15 year old girl weighing $40 \mathrm{kgs}$ in the intensive phase of antitubercular treatment for TB meningitis receiving 3 tablets per day presented with bilateral defective vision after 2 months of initiation of therapy. On examination she had defective colour vision bilaterally and the visual acuity for right eye was $1 \mathrm{~m} \mathrm{CF}$ and 6/36 with the left eye. The fundus examination showed a temporal pallor in both the eyes suggestive of progression to optic atrophy. Ethambutol was stopped immediately and treated with oral prednisolone $40 \mathrm{mg}$, zinc $(20 \mathrm{mg})$ and vitamin B complex. The patient is yet to show a significant improvement in vision during follow-up.

\section{Case 4}

30 year old male weighing $45 \mathrm{kgs}$ on intensive phase of antituberculosis therapy (ATT) with 3 FDCs daily for extra pulmonary tuberculosis, presented with bilateral blurring of vision within one week of treatment. On examination he had normal visual acuity and color vision, but he had bilateral field defects. Ethambutol was stopped and therapy continued with other drugs. The patient was treated with oral prednisolone $(40 \mathrm{mg})$, zinc $(20 \mathrm{mg})$ and vitamin B complex supplements were also given. His visual complaints are yet to improve.

\section{DISCUSSION}

Ethambutol is one of the most important first line drug used in the treatment of tuberculosis. Though it produces very less side effects, optic neuritis is a major concern. The incidence of optic neuritis is dose dependant and the incidence decreases as the dose is decreased. The incidence is reported to be $15 \%$ for patients on $50 \mathrm{mg} / \mathrm{kg}$, $5 \%$ for patients on $25 \mathrm{mg} / \mathrm{kg}$ and less than $1 \%$ in patients treated with $15 \mathrm{mg} / \mathrm{kg} /$ day. $^{6}$. The time of onset of ehambutol induced optic neuritis is not predictable, but it usually starts between 4 to 12 months after initiation of 
therapy, but can also occur as early as within days of therapy. ${ }^{7,9,10}$ The other factors which can contribute to this adverse effect are the age of the patient, duration of treatment, the renal status, alcohol and smoking habits of the patient, other concurrent illness like hypertension, and diabetes in the patient. ${ }^{11}$

Patients usually present with progressive painless loss of vision, identified initially as blurring of vision during reading suggestive of central field defects. Generally both the eyes are affected simultaneously but onset may also be unilateral. Since the most common presentation is retro bulbar neuritis fundal examination may be normal. ${ }^{7}$ Central fibres are affected generally which causes a decrease in visual acuity and central scotoma. But rarely peripheral fibres can also be affected, presenting as peripheral field constriction. It can progress to optic atrophy which manifests as temporal pallor of the disc during fundoscopic examination., ${ }^{7,12}$

Ethambutol induced optic neuritis is usually reversible, once the drug is withdrawn and recovery is time consuming. ${ }^{6}$ Irreversible cases of ethambutol induced optic neuritis have also been reported especially with advancing age. ${ }^{10}$

The mechanism behind ethambutol induced optic neuritis is not clearly understood. There are several postulates put forward one such postulate is that ethambutol and its metabolite have a zinc chelating effect causing dysregulation of retinal homeostasis. ${ }^{7,12}$ Ethambutol is also said to interfere with iron containing complex I and copper containing complex IV and thus disrupting the oxidative phosphorylation and generating reactive oxygen species leading to retinal ganglion cell damage. ${ }^{7}$

Here we are discussing four cases of ethambutol induced optic neuritis. All the four patients were on Anti tubercular treatment according to the new RNTCP guidelines. The four patients unanimously presented with defect in visual acuity with or without defects in colour vision and visual field defects except for the one patient who presented early in therapy whose main complaint was central field defects. In all these four cases the total dose of ethambutol had not exceeded the upper limit of 25 $\mathrm{mg} / \mathrm{kg}$ or a daily dose of $1500 \mathrm{mg}$ contradicting the fact that optic neuritis with ethambutol is dose related. One case presented with optic neuritis within one week of starting of ATT contrary to the reports that they present with optic neuritis usually late in therapy. Fundal examination was normal in all the cases except for the one with tuberculous meningitis where it can be attributed to the underlying disease. ${ }^{13}$ These patients were treated with oral prednisolone, oral zinc and vitamin B complex along with withdrawal of the offending drug. ${ }^{14}$ None of these patients showed any significant improvement in their visual defects which is in accordance to the fact that the recovery is very slow and time consuming.

\section{CONCLUSION}

Ethambutol induced optic neuritis is one of the major concerns during antitubercular therapy. It can lead to significant visual impairment and sometimes can lead to irreversible loss vision. Early detection, withdrawal of ethambutol, prompt treatment started and continuous ophthalmological monitoring can reverse this condition and improve the vision of this patient. So all the patients receiving ATT should undergo a pre-treatment ophthalmological evaluation with all the risk factors identified. The dosage of ethambutol can be adjusted based on the risk factor evaluation. The role of other drugs like memantine and trimetazidine may also be considered for the treatment of this adverse effect. Patient should be educated to appreciate the symptoms and report to the hospital as early as possible for ophthalmic evaluation and early detection of optic neuritis.

Funding: No funding sources

Conflict of interest: None declared

Ethical approval: Not required

\section{REFERENCES}

1. Chatterjee S, Poonawala H, Jain Y. Drug-resistant tuberculosis: is India ready for the challenge? BMJ Glob Heal. 2018;3(4):e000971.

2. Chaudhuri A. Recent changes in technical and operational guidelines for tuberculosis control programme in India - 2016: A paradigm shift in tuberculosis control. J Assoc Chest Physicians. 2017;5:1.

3. Jnawali HN. First- and Second-Line Drugs and Drug Resistance. In: Vats SRE-BHME-MG, editor. Rijeka: Intech Open; 2013: 10.

4. Central TB division, Ministry of Health and Family Welfare. RNTCP updated TB Guidelines 2019. 2019.

5. Diel R. Treatment of tuberculosis. Pneumologe. 2019;16(2):117-30.

6. Goodman BL, Knollmann BC. Goodman \& Gilman's the pharmacological basis of therapeutics.13th Edition. New York: McGraw-Hill Medical; 2018: 1074.

7. Koul PA. Ocular toxicity with ethambutol therapy: Timely recaution. Lung India. 2015;32(1):1-3.

8. Melamud A, Kosmorsky GS, Lee MS. Ocular Ethambutol Toxicity. Mayo Clin Proc. 2003;78(11):1409-11.

9. Song W, Si S. The rare ethambutol-induced optic neuropathy: A case-report and literature review. Medicine (Baltimore). 2017;96(2):5889.

10. Schild HS, Fox BC. Rapid-onset reversible ocular toxicity from ethambutol therapy. Am J Med. 1991;90(3):404-6.

11. Talbert Estlin KA, Sadun AA. Risk factors for ethambutol optic toxicity. Int Ophthalmol. 2010;30(1):63-72. 
12. Makunyane $\mathrm{P}$, Mathebula S. Update on ocular toxicity of ethambutol. African Vis Eye Heal. 2016;75(1):353

13. Schoeman JF, Andronikou S, Stefan DC, Freeman N, van Toorn R. Tuberculous Meningitis-Related Optic Neuritis: Recovery of Vision With Thalidomide in 4 Consecutive Cases. J Child Neurol. 2010;25(7):8228.

14. Undrakonda V, Yashodhara BM, Gonsalves S, Umakanth S, Kapoor S. Bilateral retrobulbar neuritis following cessation of ethambutol. Int J Case Reports Images. 2015;6(2):76.
15. Vijayakumar AR, Anuradha H, Biswas NR, Menon V, Saxena R, Halder N, et al. Evaluation of the protective effect of NMDA/non-NMDA receptor antagonists against ethambutol induced retinal toxicity using ERG in wistar rats. Indian $\mathrm{J}$ Physiol Pharmacol. 2016;60(3):268-81.

Cite this article as: Sruthi N, Anuradha M.

Ethambutol induced optic neuritis: a case series.

Int J Basic Clin Pharmacol 2020;9:207-10. 